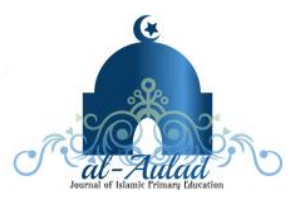

\title{
PENGARUH TEAM ASSISTED INDIVIDUALIZATION TERHADAP MOTIVASI BELAJAR SISWA PADA PEMBELAJARAN TEMATIK
}

\author{
Fia Alifah Putri ${ }^{1}$ \\ ${ }^{1}$ Jurusan Pendidikan Guru Madrasah Ibtidaiyah, Pascasarjana UIN Sunan Kalijaga, Yogyakarta \\ fiaalifahputri24@gmail.com
}

Naskah diterima: tanggal 2 September 2018, direvisi: tanggal 7 September 2018, diterbitkan: tanggal 31 Oktober 2018

\begin{abstract}
The purpose of this research is to know students learning motivation during the implementation of the Team Assested Individualization (TAI), ant then students learning motivation without using TAI, lasty, the influence of TAI to their motivation in thematic learning. The method used is a Quasi Experiment Research with the design of The Nonequivalent Pretest-Posttest Control Group Design, Non Probality sample with Purposive Sampling technique and analyzed using Independent Sample T-Test. Based on the results of the research can be summarized as follows, 1) The implementation of the TAI in thematic learning for teacher activities on average $96 \%$ and for student activities on averagec $83 \%$. 2) Motivation of students with conventional learning models before learning by 54.59 and after learning by 58.43. 3) Motivation of students with the TAI learning model before learning by 54.49 in the high category and after learning by 65.31 in the very high category. 4) There is influence, with the Independent Sample T-Test of 0,000 smaller than the 0.05 sig. Where the experimental group amounted to 65.31 is influential than the control class amounted to 58.43.
\end{abstract}

Keywords: Madrasah Ibtidaiyah, Motivation, Thematic Learning, TAI

\section{ABSTRAK}

Tujuan penelitian ini adalah untuk mengetahui motivasi belajar siswa pada pelaksanaan model pembelajaran TAI, motivasi belajar siswa tanpa menggunakan model pembelajaran dan dengan menggunakan model pembelajaran TAI, serta pengaruh model pembelajaran TAI terhadap motivasi belajar siswa pada pembelajaran tematik. Metode yang digunakan dalam penelitian ini adalah Penelitian Quasi Eksperimen dengan desain The Nonequivalent Pretest-Posttes Control Group Design, dengan teknik Purposive Sampling dan dianalisis menggunakan Independent Sample T-Test. Berdasarkan hasil penelitian diperoleh simpulan bahwa 1) Pelaksanaan model pembelajaran TAI pada pembelajaran tematik untuk aktivitas guru rata-rata $96 \%$ dan untuk aktivitas siswa dengan rata-rata 83\%. 2) Motivasi siswa dengan model pembelajaran konvensional sebelum pembelajaran sebesar 54,59 dan setelah pembelajaran sebesar 58,43. 3) Motivasi siswa dengan model pembelajaran TAI sebelum pembelajaran sebesar 54,49 pada kategori tinggi dan sesudah pembelajaran sebesar 65,31 pada kategori sangat tinggi. 4) Terdapat pengaruh, dengan hasil uji Independent Sample T-Test sebesar 0,000 lebih kecil dari nilai sig 0,05. Dimana kelompok eksperimen sebesar 65,31 lebih berpengaruh dibandingkan kelas kontrol sebesar 58,43.

Kata Kunci: Madrasah Ibtidaiyah, Motivasi Belajar, Pembelajaran Tematik, TAI.

\section{PENDAHULUAN}

Motivasi merupakan tindakan atau proses memberi seseorang dorongan untuk berbuat sesuatu. Motivasi ini dapat membangkitkan keinginan dan energi pada diri seseorang untuk melakukan pekerjaan, peran, atau subjek untuk mencapai tujuan. Dengan demikian motivasi merupakan kekuatan atau daya yang timbul dari dalam sehingga menimbulkan seseorang ingin melakukan sesuatu (Srivastava, 2018:214). 
Peningkatan motivasi memerlukan proses pembelajaran yang dapat membangkitkan gairah belajar salah satunya dengan menggunakan model pembelajaran yang menarik bagi siswa. Zhou bependapat dalam jurnalnya bahwa, Learning process using cooperative learning model is considered effective because it can increase the variables that contribute to motivation, improve achievement and generate a positive social surrounding (Zhou, 2012:1322). Menurut Zhou model pembelajaran kooperatif dapat meningkatkan salah satu variabel proses pembelajaran yaitu motivasi yang ada dalam diri siswa.

Model pembelajaran kooperatif dapat membentuk siswa menjadi pribadi yang saling bekejasama dan tidak saling berkompetisi. Salah satunya dengan menggunakan model pembelajaran kooperatif tipe TAI yang mempunyai karakteristik tanggung jawab belajar berada pada tiap individu para siswa untuk membantu siswa lain yang kurang dalam pembelajaran (Azmidar et al., 2018:2). Adapun model pembelajaran kooperatif tipe TAI yang diarahkan kepada siswa untuk memecahkan masalah yang diberikan oleh guru dalam kelompok kecil. Pembelajaran ini mengharuskan siswa untuk berpartispasi aktif di dalam kelas (Tinungki, 2015:27).

Partipasi aktif yang diberikan oleh siswa pada proses pembelajaran membuat pembelajaran pun menjadi menyenangkan dan aktif. Seperti yang dikatakan oleh Indriani bahwa perubahan kurikulum dari KTSP menjadi kurikulum 2013 mendatangkan akibat tersendiri bagi guru. Dimana dalam proses pembelajarannya guru dituntut melaksanakan pembelajaran yang aktif dengan pendekatan saintifik dan penilaian otentik (Indriani, 2015:87). Kurikulum 2013 sendiri dirancang untuk meningkatkan kurikulum pendidikan yang ada di Indonesia sebelumnya. Dalam kegiatan proses pembelajaran K-13 berbasis pembelajaran tematik. Pembelajaan tematik meupakan suatu kesatuan berbagai bidang mata pelajaran yang ada disekolah, dan diatur sedemikian rupa agar siswa dapat melihat hubungan antara berbagai bidang mata pelajaran dalam kehidupan nyata (Helmane, 2017:70).

Pembelajaran tematik yang dilaksanakan pada proses pembelajaran haruslah menyenangkan dan efektif dengan pemilihan model yang tepat untuk merangsang dan menumbuhkan motivasi siswa. Pembelajaran kooperatif tipe (TAI) diciptakan untuk menyelesaikan masalah-masalah dalam sistem pengajaran individual salah satunya adalah harapan agar para siswa akan termotivasi untuk mendalami materi-materi yang diberikan dengan waktu singkat dan tepat, dan tidak akan bisa melakukan hal- hal kecurangan atau bertindak yang tidak sesuai dengan aturan (Slavin, 2015:190-191).

Berdasarkan studi pendahuluan yang peneliti lakukan di MIN 1 Kota Bandung diketahui bahwa motivasi belajar siswa masih rendah. Hal ini dapat dilihat dalam proses pembelajaran yang terjadi antara guru dan siswa bersifat satu arah, pembelajaran yang minim media dan model pembelajaran tidak beragam membuat siswa tidak aktif, sibuk sendiri dan tidak antusias dalam proses belajar mengajar. Selain itu siswa tidak termotivasi untuk belajar dengan teman yang lain terutama siswa laki-laki dan perempuan sulit untuk bekejasama, mereka cenderung berseteru sehingga berdampak pada proses pembelajaran yang kurang efektif dan menyenangkan di dalam kelas. Hal ini menunjukan ada beberapa indikator motivasi seperti devosi (pengabdian) pemikiran untuk mencapai tujuan yang ingin dicapai, tingkat aspirasi, keuletan melakukan kegiatan pembelajaran siswa belum terpenuhi dengan baik sehingga menyebabkan arah sikap motivasi cenderung condong ke arah negatif.

Penelitian ini didukung oleh beberapa penelitian yang relevan seperti penelitian yang dilakukan oleh Tinungki yang berjudul "The Role of Coopeative Learning Type Team Assested Individualization to Improve the Students' Mathematics Communication Ability in 
the Subject of Probability Theory" yang dimuat dalam Journal of Education and Practice. Dari hasil penelitian tesebut diketahui bahwa kemampuan komunikasi matematika memiliki korelasi yang signifikan dengan pembelajaran koopeatif tipe TAI (Tinungki, 2015:30)

Didukung pula oleh penelitian yang dilakukan oleh Subarni yang berjudul "Peningkatan Motivasi Dan Kemampuan Menyimak Cerita dengan Model Pembelajaran TAI (Team Assisted Individualization) Pada Mata Pelajaran Bahasa Jawa Kelas V SD Negeri Putuk Kecamatan Nguntoronadi, Wonogiri Tahun Pelajaran 2015/2016" yang dimuat dalam Indonesian Journal on Education and Research. Dari hasil penelitian tersebut dapat disimpulkan bahwa melalui model pembelajaran TAI ( Team Assisted Individulaization) terbukti dapat meningkatkan motivasi belajar dan kemampuan menyimak cerita siswa pada mata pelajaran bahasa jawa dengan peningkatan dari 60 menjadi 75 (Subarni, 2017:52).

Perbedaan penelitian yang dilakukan oleh peneliti dengan penelitian sebelumnya terdapat pada mata pelajaran yang diambil. Bahwa belum ada yang meneliti tentang pengaruh model pembelajaran TAI terhadap motivasi belajar siswa pada pembelajaran tematik tetapi cukup banyak yang menggunakannya pada mata pelajaran matematika atau yang lainnya. Oleh karena itu peneliti berniat akan melakukan penelitian tersebut dengan judul pengaruh model pembelajaan TAI terhadap motivasi belajar siswa.

\section{METODOLOGI}

Metode penelitian pada penelitian ini menggunakan eksperimen semu atau quasi eksperimen dengan desain The Nonequivalent Pretest-Posttest Control Group Design. Desain ini dapat diilustrasikan sebagai berikut :

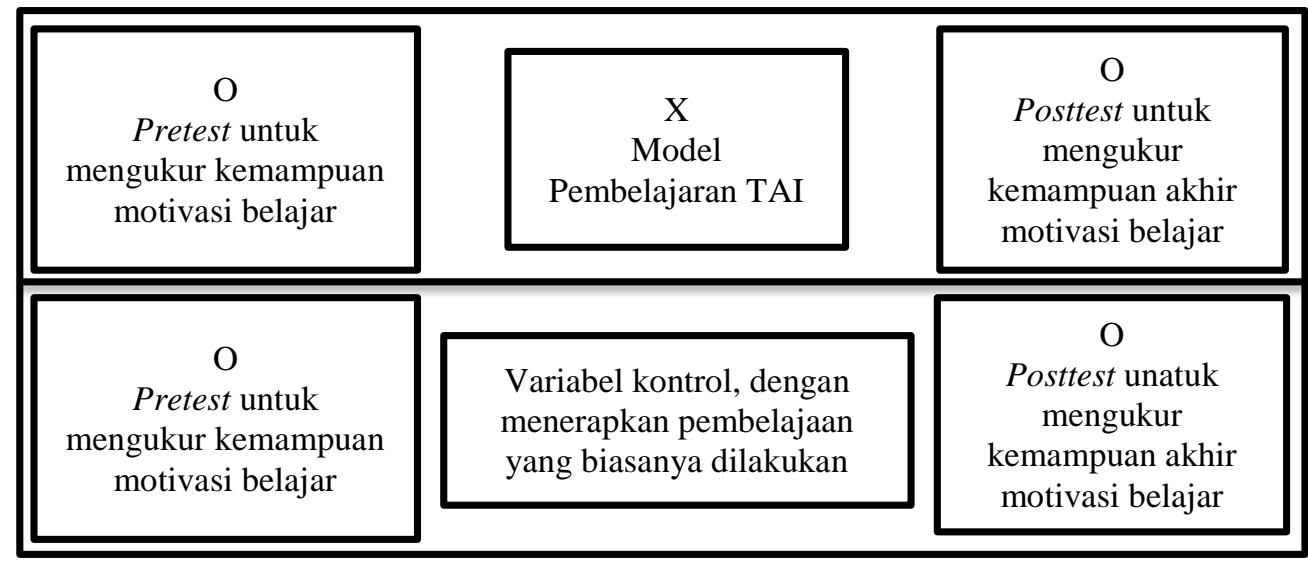

Gambar 1. Ilustrasi The Nonequivalent Pretest-Posttest Control Group Design

Pada Desain ini sebelum mengerjakan penelitian kedua kelompok diberi pretest $(\mathrm{O})$ untuk mengetahui motivasi belajar siswa pada pembelajaran tematik dengan menggunakan lembar angket motivasi belaja siswa. Selama penelitian dilaksanakan, kelompok pertama diberikan perlakuan (X) berupa model pembelajaran TAI sebagai kelas ekspeimen dan kelompok yang lain tidak diberi perlakuan tanpa model pembelajaran TAI sebagai kelas kontrol. Kemudian di akhir penelitian, kedua kelas diberi posttest (O) untuk melihat bagaimana hasil peningkatan motivasi belajar dengan menggunakan lembar angket (Lestari \& Yudhanegara, 2017:138-139).

Lokasi penelitian ini adalah MIN 1 Kota Bandung yang beralamatkan di jalan Sindang Sari No.12 Kelurahan Cipadung Kulon Kecamatan Panyileukan Kota Bandung Propinsi Jawa Barat. Penentuan lokasi tesebut didasarkan pada masalah yang peneliti temui 
pada saat PPL selama kurang lebih 3 bulan. Waktu penelitian dilaksanakan pada semester genap tahun ajaran 2018 yaitu antara bulan April sampai dengan bulan Mei 2018.

Jenis data penelitian yang digunakan dalam penelitian ini adalah jenis data kuantitatif dan kualitatif. Data kuantitatif yakni data pretest dan posttest, yaitu lembar angket yang digunakan untuk mengukur skala motivasi belajar siswa pada pembelajaan tematik di kelas eksperimen maupun kontrol. Data kualitatif dalam penelitian ini didapatkan dari hasil observasi yang dilakukan oleh observer terhadap siswa dan guru.

Sumber data penelitian yang peneliti gunakan dalam penelitian ini meliputi populasi dan sampel. Populasi dalam penelitian ini adalah siswa kelas III MIN 1 Kota Bandung yang berjumalah 112 siswa. Dan sampel yang peneliti gunakan adalah non probality sampel dengan teknik purposive sampling yang merupakan teknik penentuan sampel dengan pertimbangan-pertimbangan tertentu (Lestari \& Yudhanegara, 2017:110). Adapun petimbangan yang peneliti butuhkan adalah dua kelas berbeda yang memiliki karakteristik dan permasalahan yang sama agar dapat dijadikan sebagai kelas eksperimen dan kelas kontrol. Berdasarkan pertimbangan yang peneneliti butuhkan ini, maka peneliti menetapkan kelas IIIC MIN 1 Kota Bandung yang berjumlah 35 siswa sebagai kelas eksperimen dan kelas IIIB MIN 1 Kota Bandung yang berjumlah 37 siswa sebagai kelas kontrol.

Teknik pengumpulan data pada penelitian ini adalah teknik non tes yaitu observasi dan angket. Untuk dapat menganalisis data hasil observasi agar dapat mengetahui bagaimana pelaksanaan pembelajaran TAI terhadap para siswa dan guru pada pembelajaran tematik disini peneliti menggunakan lembar observasi. Cara mengelola data hasil observasi menggunakan rumus sebagai berikut :

$$
\mathrm{NP}=\frac{R}{S M} \times 100 \%
$$

Keterangan :

$\mathrm{NP}=$ Nilai persen keterlaksanaan yang dicari

$\mathrm{R}=$ Jumlah skor yang diperoleh

$\mathrm{SM}=$ Skor maksimum

Data yang diperoleh dapat diukur dengan tingkat keterlaksanaannya sebagai berikut:

Tabel 1. Tingkat Keterlaksanaan

\begin{tabular}{|c|c|c|}
\hline No & Tingkat Keterlaksanaan & Keterangan \\
\hline 1 & $86-100 \%$ & Sangat Baik \\
\hline 2 & $76-85 \%$ & Baik \\
\hline 3 & $60-75 \%$ & Cukup \\
\hline 4 & $55-59 \%$ & Kurang \\
\hline 5 & $<54 \%$ & Kurang Sekali \\
\hline
\end{tabular}

Sumber: Purwanto, 2009

Sedangkan untuk menganalisis data yang didapat dari angket untuk mengetahui bagaimana pengaruh motivasi belajar siswa sebelum dan setelah menggunakan model TAI dan tanpa menggunakan model TAI peneliti disini menggunakan lembar angket. Dimana lembar angket tersebut diuji terlebih dahulu kelayakannya sebelum diberikan pada siswa dengan menggunakan uji validitas dan realibilitas. Uji validitas angket disini peneliti menggunakan validitas isi (content validity) dan validitas konstruksi (contrast validity). Adapun teknik korelasi yang digunakan untuk mencari koofesien korelasi validitas 
instrument dalam penelitian ini adalah dengan menggunakan koefesien korelasi product moment pearson dengan bantuan SPSS 20 menununjukan 18 item soal yang dinyatakan valid dan 12 item soal yang dinyatakan tidak valid.

Dilanjutkan dengan uji realibilitas dengan menggunakan rumus Alpha Cronbach dengan bantuan SPSS 20. Dan ditafsirkan dengan tingkatan hasil pehitungan uji realibilitas instrumen yang berdasarkan kriteria rentangan-rentangan nilai sebagai berikut:

Tabel 2. Kriteria Koefisien Korelasi Reliabilitas Instrumen

\begin{tabular}{|r|l|l|}
\hline \multicolumn{1}{|c|}{ Koofisien Korelasi } & \multicolumn{1}{|c|}{ Korelasi } & \multicolumn{1}{c|}{ Interpetasi } \\
\hline $0,90 \leq \mathrm{r}_{\mathrm{xy}} \leq 1,00$ & Sangat Tinggi & Sangat tepat/Sangat baik \\
\hline $0,70 \leq \mathrm{r}_{\mathrm{xy}}<0,90$ & Tinggi & Tepat/baik \\
\hline $0,40 \leq \mathrm{r}_{\mathrm{xy}}<0,70$ & Sedang & Cukup tepat/cukup baik \\
\hline $0,20 \leq \mathrm{r}_{\mathrm{xy}}<0,40$ & Rendah & Tidak tepat \\
\hline $\mathrm{r}_{\mathrm{xy}}<0,20$ & Sangat Rendah & Sangat tidak tepat/ tidak berkorelasi \\
\hline \multicolumn{2}{|c|}{ Sumber: Lestari \& Yudhanegara, 2017 }
\end{tabular}

Dari hasil uji reliabilitas untuk skala motivasi diperoleh hasil reliabilitas butir dari variabel motivasi belajar dengan nilai koefisien sebesar 0,791 atau dibulatkan menjadi 0,79 . Kemudian diinterpretasikan dengan tingkat keandalan koefisien menurut Karunia Eka termasuk kedalam kategori tinggi, karena terletak pada rentang antara 0,70 sampai dengan 0,90. Sehingga dapat disimpulkan bahwa instrumen yang digunakan reliabel dan dapat digunakan dalam penelitian.

Setelah uji validitas dan realibilitas selesai, data dianalisis dengan analisis data kuantitatif. Pengolahan data dilakukan dengan menganalisis data posttest untuk mengetahui pengaruh motivasi belajar siswa pada kelas eksperimen dan kontrol. Dalam analisis penelitian ini, setelah pretest dan posttest tentang motivasi belajar siswa pada pembelajaran tematik telah terkumpul baik dari kelas eksperimen maupun kelas kontrol, maka dilakukan pengolahan data dengan bantuan Microsoft Excel 2010 dan SPSS 20. Untuk mengetahui interval kategori motivasi belajar siswa, peneliti menggunakan kategori motivasi belajar sebagai berikut:

Tabel 3. Kategori Motivasi Belajar

\begin{tabular}{|c|c|}
\hline Rentang Skor Nilai & Kategori \\
\hline$+1,5 \sigma<\mu$ & Sangat Tinggi \\
\hline$+0,5 \sigma<\mu \leq+1,5 \sigma$ & Tinggi \\
\hline$-0,5 \sigma<\mu \leq+0,5 \sigma$ & Sedang \\
\hline$-1,5 \sigma<\mu \leq-0,5 \sigma$ & Rendah \\
\hline$\mu \leq-1,5 \sigma$ & Sangat Rendah \\
\hline
\end{tabular}

Sumber: Azwar, 2015

Keterangan:

$\mu$ (mean ideal)

$\sigma$ (standar deviasi ideal)

$$
\begin{aligned}
& =\frac{1}{2}(\text { skor maksimal }+ \text { skor minimal }) \\
& =\frac{1}{6}(\text { skor maksimal }- \text { skor minimal })
\end{aligned}
$$

Setelah tahap diatas selesai kemudian dilakukan pengujian hipotesis, pengujian ini menggunakan bantuan Microsoft Excel 2010 dan SPSS 20 dengan menggunakan rumus Independent Sampel T-Test. Syarat yang dilakukan sebelum melakukan uji-t adalah uji normalitas dan homogenitas data. Uji normalitas dilakukan dengan menggunakan rumus Kolmogorov Smirnov, sedangkan uji homogenitas menggunakan rumus uji Levene statistic. 


\section{HASIL DAN DISKUSI}

Berdasarkan hasil penelitian yang dilakukan dilapangan tentang pengaruh model pembelajaran TAI terhadap motivasi belajar siswa pada kelas eksperimen dan kelas kontrol diperoleh data sebagai berikut :

1. Data Hasil Pelaksanaan Model Pembelajaran TAI terhadap Motivasi Belajar Siswa

Pelaksanaan proses pembelajaran dengan pemberian perlakuan menggunakan model TAI pada kelas eksperimen dilaksanakan 2 kali pertemuan, setiap pertemuan selama 2 jam lebih 20 menit. Mata pelajaran yang dibahas yaitu pembelajaran tematik, tema 8 tentang Bumi dan Alam Semesta, subtema tentang Ketampakan Rupa Bumi pembelajaran pertama dan pembelajaran kedua.

Pertemuan pertama hasil lembar observasi guru kelas eksperimen sebesar 92\% dan meningkat pada pertemuan kedua sebesar $100 \%$, maka jika dirata-ratakan aktivitas guru pertemuan pertama dan kedua akan menghasilkan nilai sebesar 96\% dan masuk dalam kategori keterlaksanaan sangat baik yakni berada pada rentang 86-100\%. Sedangkan hasil lembar observasi aktivitas motivasi belajar siswa pada kelas eksperimen pertemuan pertama sebesar $77 \%$ dan meningkat pada pertemuan kedua sebesar $89 \%$, maka jika dirataratakan pertemuan pertama dan kedua akan menghasilkan nilai sebesar 83\% masuk kedalam kategori baik yakni berada pada rentang 76-85\%. Agar lebih jelas peneliti memaparkannya menggunakan tabel sebagai berikut:

Tabel 4. Hasil Aktivitas Guru dan Siswa Pada Pertemuan Pertama dan Kedua

\begin{tabular}{|c|c|c|}
\hline \multirow{2}{*}{ Penilaian Aktivitas Guru } & Pertemuan Pertama & Pertemuan Kedua \\
\cline { 2 - 3 } & Skor Total & Skor Total \\
\cline { 2 - 3 } & 13 & 14 \\
\hline Persentase & $92 \%$ & $100 \%$ \\
\hline Rata-Rata Nilai Persentase & \multicolumn{2}{|c|}{$96 \%$} \\
\hline \multirow{3}{*}{ Penilaian Aktivitas Siswa } & Pertemuan Petama & Pertemuan Kedua \\
\cline { 2 - 3 } & Skor Total & Skor Total \\
\cline { 2 - 3 } & 34 & 83 \\
\hline Persentase & $77 \%$ & $89 \%$ \\
\hline Rata-Rata Nilai Persentase & \multicolumn{2}{|c|}{$83 \%$} \\
\hline
\end{tabular}

2. Motivasi Belajar Siswa Pada Kelas Eksperimen dan Kelas Kontrol

Sebelum pembelajaran dimulai, siswa diberikan skala motivasi belajar (pretest) untuk mengetahui motivasi belajar siswa pada pembelajaran tematik baik pada kelas eksperimen maupun kontrol. Setelah diberi perlakuan selama 2 kali petemuan pada akhir pembelajaran siswa diberikan kembali skala motivasi belajar (posttest).

Pretest skala motivasi belajar, pada kelas eksperimen mempunyai kategori motivasi sangat tinggi ada 1 siswa $(2,8 \%)$ sedangkan pada kelas kontrol yang mempunyai kategori sangat tinggi ada 2 siswa $(5,4 \%)$. Dan yang mempunyai kategori motivasi tinggi pada kelas eksperimen sebanyak 32 siswa $(91,4 \%)$ sedangkan pada kelas kontrol kategori tinggi ada 32 siswa $(86,5 \%)$. Dan kategori motivasi sedang ada 2 siswa $(5,7 \%)$ sedangkan pada kelas kontrol ada 3 siswa $(8,1 \%)$. Dengan nilai rata-rata pretest kelas eksperimen sebesar 54,49 dan kelas kontrol sebesar 54,59 berada pada kategori tinggi. Berikut penjelasannya dalam grafik batang: 


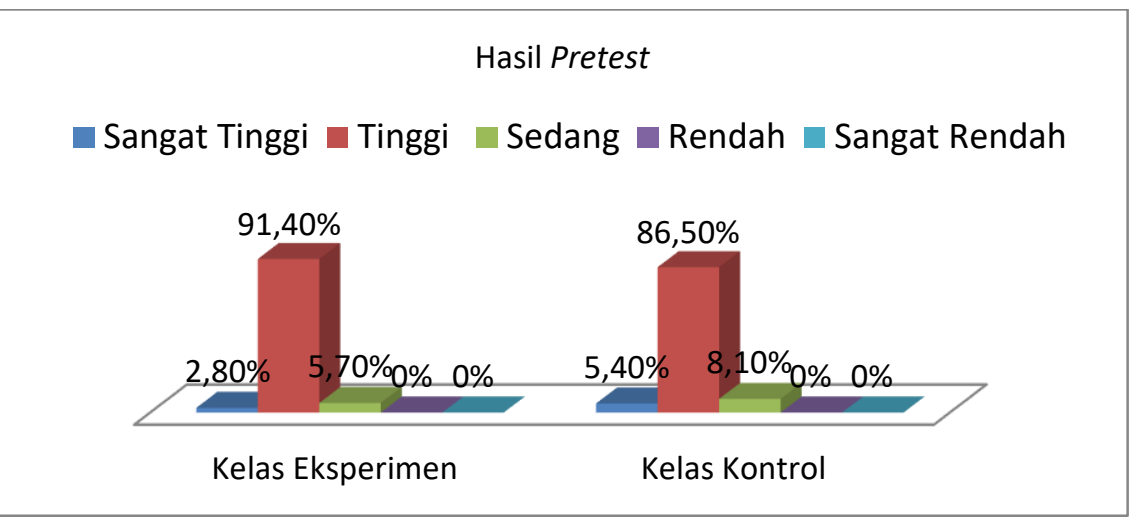

Gambar 2. Hasil Pretest Motivasi Belajar Siswa Pada Kelas Eksperimen dan Kelas Kontrol

Posttest skala motivasi belajar pada kelas eksperimen dan kelas kontrol di atas, yang mempunyai kategori motivasi sangat tinggi berjumalah 35 siswa (100\%) berada pada kelas eksperimen sedangkan kategori sangat tinggi kelas kontrol hanya 54\% kategori motivasi tinggi $40 \%$ dan kategori motivasi sedang 5,4\%. Dengan nilai rata-rata posttest kelas eksperimen sebesar 65,31 berada pada kategori sangat tinggi dan pada kelas kontrol sebesar 58,43 berada pada kategori tinggi. Berikut penjelasannya dalam grafik batang:

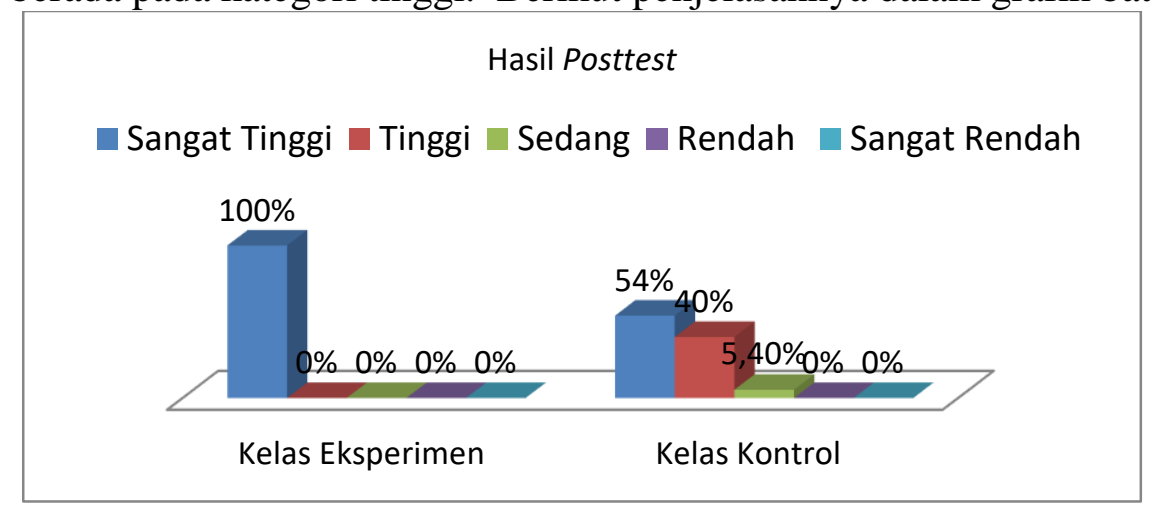

Gambar 3. Hasil Posttest Motivasi Belajar Siswa Pada Kelas Ekspeimen dan Kelas Kontrol

\section{Pengaruh Motivasi Belajar Siswa Pada Kelas Eksperimen dan Kelas Kontrol}

Penelitian ini dilakukan dalam dua kelas yaitu kelas eksperimen dan kelas kontrol. Pada kelas eksperimen peneliti menggunakan model pembelajaran TAI sedangkan pada kelas kontrol menggunakan model pembelajaran konvensional. Untuk mengetahui apakah benar ada pengaruh yang signifikan antara motivasi belajar siswa pada kelas eksperimen dan kelas kontrol maka peneliti melakukan uji hipotesis menggunakan Independent Sample $T$-Test. Untuk melakukannya terlebih dahulu peneliti melakukan uji normalitas dan homogenitas.

Uji normalitas data dilakukan pada data posttest kelas eksperimen dan kelas kontrol. Hasil uji normalitas data dengan bantuan SPSS 20 menggunakan rumus Kolmogorov Smirnov adalah sebagai berikut:

Tabel 5. Hasil Uji Normalitas Data

\begin{tabular}{|c|l|c|c|c|}
\hline \multirow{4}{*}{ Motivasi Belajar Siswa } & \multicolumn{1}{|c|}{ Kelas } & \multicolumn{3}{|c|}{ Kolmogoov-Smirnov } \\
\cline { 2 - 5 } & \multicolumn{1}{|c|}{ Statistik } & df & Sig. \\
\cline { 2 - 5 } & Post-test Kelas Eksperimen (TAI & .135 & 35 & .109 \\
\cline { 2 - 5 } & $\begin{array}{l}\text { Post-test Kelas Kontrol } \\
\text { Konvensional }\end{array}$ & .125 & 37 & .152 \\
\hline
\end{tabular}


Berdasarkan tabel tersebut, nilai signifikasi (sig) posttest kelas eksperimen 0,109 dan sig posttest kelas kontrol 0,152 lebih besar dari 0,05. Ini menunjukan bahwa data posttest kelas eksperimen dan kelas kontrol berdistribusi normal.

Setelah uji normalitas dinyatakan normal maka peneliti langsung melakukan uji homogenitas. Uji homogenitas dilakukan untuk mengetahui apakah variasi data dari sampel yang dianalisis homogen atau tidak. Hasil uji homogenitas menggunakan uji levene statistic dengan bantuan SPSS 20 adalah sebagai berikut:

Tabel 6. Hasil Uji Homogenitas data

\begin{tabular}{|c|l|c|c|c|c|}
\hline \multirow{4}{*}{ Kelas } & \multicolumn{4}{|c|}{ Kolmogoov-Smirnov } \\
\cline { 2 - 6 } Motivasi Belajar Siswa & Statistik & df1 & df2 & Sig. \\
\cline { 2 - 6 } & Based on Mean & 5.573 & 1 & 70 & .021 \\
\cline { 2 - 6 } & Based on Median & 4.993 & 1 & 70 & .029 \\
\cline { 2 - 6 } & $\begin{array}{l}\text { Based on Median and with adjusted } \\
\text { df }\end{array}$ & 4.993 & 1 & 59.212 & .029 \\
\cline { 2 - 6 } & Based on trimmed mean & 5.524 & 1 & 70 & 0.22 \\
\hline
\end{tabular}

Berdasarkan tabel tersebut, nilai homogenitas data posttest motivasi belajar siswa sebesar 0,021 lebih kecil dari 0,05. Ini menunjukan bahwa data homogenitas posttest tidak homogen, yang berarti $H_{0}$ ditolak

Setelah dilakukan uji normalitas dan uji homogenitas, ternyata kelas eksperimen maupun kontrol sama-sama berdistribusi normal namun sama-sama tidak homogen. Maka dari itu kita bisa langsung menuju Independent Sample T-Test untuk mencari tahu apakah posttest pada kelas eksperimen maupun kelas kontrol terdapat pengaruh atau tidak.

Tabel 7. Hasil Analisis Independent Sample T-Test

\begin{tabular}{|c|l|c|c|c|c|c|}
\hline \multicolumn{2}{|c|}{} & $\begin{array}{c}\text { Levene's Test for } \\
\text { Equality of Variances }\end{array}$ & \multicolumn{4}{|c|}{} \\
\cline { 3 - 8 } \multicolumn{2}{|c|}{} & $\mathrm{F}$ & Sig. & $\mathrm{t}$ & $\mathrm{df}$ & $\begin{array}{c}\text { Sig. (2- } \\
\text { tailed }\end{array}$ \\
\hline $\begin{array}{c}\text { Motivasi } \\
\text { Belajar Siswa }\end{array}$ & Equal variances assumed & 5.573 & .021 & 6.134 & 70 & .000 \\
\cline { 2 - 8 } & Equal variances not assumed & & & 6.207 & 61.656 & .000 \\
\hline
\end{tabular}

Berdasarkan tabel tersebut karna data yang peneliti teliti tidak homogen maka untuk independent sample t-test ini peneliti melihat data equal variances not assumed dan dipeoleh nilai sig (2-tailed) sebesar $0,000<0,05$, maka ini berarti $H_{0}$ ditolak atau dengan kata lain terdapat pengaruh antara model pembelajaan TAI terhadap motivasi belajar siswa. Untuk mengetahui seberapa besar pengaruh antara motivasi belajar siswa pada kelas eksperimen dan motivasi belajar siswa pada kelas kontrol. Kita dapat melihat hasil ratarata nilai data dengan analisis statistik deskriptif adalah sebagai berikut:

Tabel 8. Hasil Analisis Statistik Deskriptif

\begin{tabular}{|c|l|c|c|}
\hline \multirow{2}{*}{$\begin{array}{c}\text { Motivasi Belajar } \\
\text { Siswa }\end{array}$} & Kelas & N & Mean \\
\cline { 2 - 4 } & Post-test Kelas Eksperimen (TAI) & 35 & 65.31 \\
\cline { 2 - 4 } & Post-test Kelas Kontrol (Konvensional) & 37 & 58.43 \\
\hline
\end{tabular}

Nilai rata-rata motivasi belajar siswa di kelas eksperimen adalah 65,31 dan kelas kontrol 58,43 yang berarti nilai motivasi belajar siswa pada kelas eksperimen lebih besar dibandingkan nilai rata-rata kelas kontrol. Hal tersebut menunjukan bahwa motivasi belajar 
siswa pada kelas eksperimen menggunakan model pembelajaran TAI jauh lebih baik dibandingkan menggunakan pembelajaran konvensional pada kelas kontrol.

\section{KESIMPULAN}

Berdasarkan hasil penelitian yang telah dilakukan dapat diambil kesimpulan bahwa, pelaksanaan model pembelajaran TAI dalam proses pembelajaran tematik sudah terlaksana dengan baik. Hal ini terlihat pada pertemuan pertama aktivitas guru sebesar 92\% dan meningkat pada pertemuan kedua sebesar $100 \%$ dengan nilai rata-rata sebesar $96 \%$ yang berada pada kategori sangat baik. Sedangkan nilai persentasi pada pertemuan pertama pada observasi aktivitas siswa sebesar $77 \%$ dan meningkat pada pertemuan kedua sebesar $89 \%$ dengan nilai rata-rata $83 \%$ yang berada pada kategori baik. Motivasi siswa pada pembelajaran tematik dengan menggunakan model pembelajaran konvensional tidak terlalu menunjukan hasil perbedaan yang jauh. Hal ini terlihat dari hasil rata-rata sebelum pembelajaran hasilnya sebesar 54,59 berada pada kategori tinggi dan sesudah pembelajaran hasilnya sebesar 58,43 berada pada kategori tinggi. Sedangkan motivasi siswa pada pembelajaran tematik dengan menggunakan model pembelajaran TAI menunjukan peningkatan. Hal ini dapat terlihat sebelum pembelajaran dimulai hasil rata-rata yang didapat sebesar 54,49 berada pada kategori tinggi dan hasil rata-rata sesudah menggunakan model pembelajaran TAI sebesar 65,31 berada pada kategori sangat tinggi. Setelah menganalisis dengan Uji-t menghasilkan pernyataan terdapat pengaruh yang cukup tinggi dengan penggunaan model pembelajaran TAI terhadap peningkatkan motivasi belajar siswa pada pembelajaran tematik dibandingkan pembelajaran konvensional. Hal ini dapat terlihat dari hasil Independent Sample T-Test yang menyatakan bahwa hasil yang didapat sebesar 0,000 lebih kecil dari nilai signifikansi 0,05 yang berarti $H_{0}$ ditolak atau dengan kata lain terdapat pengaruh antara motivasi belajar siswa pada kelas eksperimen dan kelas kontrol. Dimana kelompok eksperimen lebih berpangaruh besar dibandingkan kelas kontrol dengan perolehan skor kelas eksperimen sebesar 65,31 yang berada pada kategori sangat tinggi dibandingkan kelas kontrol yang hanya 58,43 yang berada pada kategori tinggi. Yang bearti motivasi belajar siswa yang menggunakan model pembelajaran TAI pada kelas eksperimen jauh lebih baik dibandingkan model pembelajaran konvensional pada kelas kontrol.

\section{DAFTAR PUSTAKA}

Azmidar, A., Darhim, D., Dahlan, J. A., Mekarina, M., Ningsih, Y. P., Juliane, C., ... Sastramihardja, H. S. (2018). The effect of team accelerated instruction on students ' mathematics achievement and learning motivation The effect of team accelerated instruction on students ' mathematics achievement and learning motivation. Jounal of Physics: Conference Series.

Helmane, I. (2017). Thematic Approach and Mathematics Textbooks in Primary School. Rural Environment Education Personality, 12-13.

Indriani, F. (2015). Kompetensi Pedagogik Mahasiswa Dalam Mengelola Pembelajaran Tematik Integratif Kurikulum 2013 Pada. Junal Profesi Pendidikan Dasar, 2(2), 8794.

Lestari, K. E., \& Yudhanegara, M. R. (2017). Penelitian Pendidikan Matematika. Bandung: PT Refika Aditama.

Slavin, R. E. (2015). Cooperative Leaning Teori, Riset, dan Praktik. Bandung: Nusa Media.

Srivastava, S. (2018). Impact of Motivation on Management Student's Academic 
Performance in Relation to Overall Advancement. International Journal of Advance Research, Ideas And Innovations In Technology, 4(1), 214-217.

Subarni. (2017). Peningkatan Motivasi Dan Kemampuan Menyimak Cerita dengan Model Pembelajaran TAI ( Team Assisted Individualization ) Pada Mata Pelajaran Bahasa JawaKelas V SD Negeri Putuk Kecamatan Nguntoronadi, Wonogiri Tahun Pelajaran 2015 / 2016. Indonesian Journal on Education and Research, 2(3), 46-53.

Tinungki, G. M. (2015). The Role of Cooperative Learning Type Team Assisted Individualization to Improve the Students 'Mathematics Communication Ability in the Subject of Probability Theory. Journal of Education and Practice, 6(32), 27-31.

Zhou, H. (2012). Enhancing Non-English Majors' EFL Motivation through Cooperative Learning. Procedia Environmental Sciences, 12 (Icese 2011), 1317-1323. https://doi.org/10.1016/j.proenv.2012.01.428 